\title{
The internet of things in high andean wetland monitoring, historical review approach
}

\author{
Vladimir Henao Céspedes, Gloria Yaneth Florez², Yeison Alberto Garcés-Gómez ${ }^{3}$ \\ ${ }^{1,3}$ Universidad Católica de Manizales-Unidad de Formación en Ciencias Naturales y Matemáticas-UAFCNM, Manizales, \\ Colombia \\ ${ }^{2}$ Universidad Católica de Manizales-Grupo de Investigación en Desarrollos Tecnológicos y Ambientales-GIDTA, \\ Manizales, Colombia
}

\begin{tabular}{l}
\hline \hline Article Info \\
\hline Article history: \\
Received May 21, 2020 \\
Revised Dec 5, 2020 \\
Accepted Mar 19, 2021 \\
\end{tabular}

Keywords:

Environment

High andean wetlands

IoT

Wetlands

Wireless sensor networks WSN

\begin{abstract}
The internet of things (IoT) has allowed important technological advances for monitoring and telemetry, thanks to the fact that IoT-based systems allow to obtain information in large areas, far from urban environments, and where low energy monitoring systems are required, features that are consistent with the requirements for high Andean wetlands telemetry. The monitoring of environmental variables, such as water quality in high Andean wetlands, is a topic of great importance for the scientific community, since, if the knowledge of the dynamics of the wetlands is improved, it is possible to optimize the decision making for their conservation. In that sense, to know the application of the IoT in this type of wetlands at a global level, this work presents a review of the literature related to the use of the IoT in the monitoring of high Andean wetlands. In order to carry out a historical review, a methodology was proposed under some guiding questions, which allowed designing a structure for background searches. Both the questions and the structure guided the search process from macro areas, such as IoT and environment, to micro areas, such as IoT applications in wetland monitoring. Finally, the review concluded that IoT has not been applied in high Andean wetland monitoring.
\end{abstract}

This is an open access article under the CC BY-SA license.

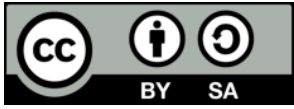

\section{Corresponding Author:}

Vladimir Henao Céspedes

UAFCNM

Universidad Católica de Manizales

Manizales-Colombia, Cra 23 No. 60-63, Colombia

Email:vhenao@ucm.edu.co

\section{INTRODUCTION}

Habitats such as swamps, peatlands, floodplains, rivers, lakes and coastal areas are called wetlands. Within the coastal areas are marshes, mangroves, and seagrass beds, but also coral reefs and other marine areas whose depth at low tide does not exceed six meters. Also, some unnatural constructions are called artificial wetlands in which wastewater treatment ponds and reservoirs can be found [1], [2]. Depending on their location, some of these are defined as high Andean wetlands, such is the case in Colombia, where some are located over the Andes Mountains. In Colombia, the high Andean wetlands are in a high degree of vulnerability, due to the fact that a part of the population has located in their vicinity, thus generating a high demand for land for agricultural production, and expanding the agricultural frontier, with the consequent drying up, contamination and destruction that such expansion generates [3]. Thus, according to [4], more than $60 \%$ of wetlands located in páramos in the upper basin of the Chinchiná River Colombia have been lost in a period of 10 years. The problem of loss of wetland coverage can be related, on one hand, to global 
warming and, on the other hand, to anthropogenic aspects. It is also an issue of great importance for the scientific community, since, if the understanding of the dynamics of wetlands is improved, it is possible to optimize decision-making for their conservation.

In order to achieve the purpose of improving the understanding of wetland dynamics, it is necessary to collect information, in a wide spatial and temporal window (large areas of land over long periods of time with high periodicity), which is possible by developing and implementing technology-based monitoring systems. Some wetland monitoring mechanisms have used techniques such as remote sensing [5], related to aerial photos, hyperspectral imaging, radar and light detection and ranging (LiDAR). On the other hand, it is possible that these monitoring systems, use other techniques from the application of the internet of things (IoT). In connection with the IoT, in 1999, Kevin Ashton, coined the concept "IoT" as part of a presentation to "Proctor \& Gamble" about incorporating radio frequency identification (RFID) tags into their supply chain [6]-[8]. On the other hand, according to CISCO's IBSG (Internet Business Solutions Group), IoT was born at a point in time when more "things or objects" than people were connected to the Internet, that point can be estimated between 2008 and 2009 [9]. In this sense, according to [10], they indicate that in 20128.7 million devices were connected to the Internet, in 2017, 20 billion devices and in 2023, an estimated 50 billion devices would connect to the Internet. Since its inception, IoT has been applied to different fields of research and development, this has led to the generation of a high volume and variety of data.

In the environmental field, given the need to measure different variables, which require important sampling frequencies in large areas of spatial coverage, IoT has proved to be a viable solution, given the low power consumption required, with good operating autonomy, which facilitates its application in places of difficult or controlled access [11], [12]. Now, another area of application of IoT, related to the environmental field [13], [14] and water quality, but not to the high Andean wetlands, is health, and it is there where authors like [15]-[18] and [19] have ventured into the design of system for monitoring water quality, based on IoT techniques. The above taking into account not only the ease of applying these developments in areas of difficult access, but also the low cost that they can have, so much so that IoT techniques are being addressed in an interesting way in telemedicine [20], [21].

This paper aims to analyze how IoT has been active in wetland monitoring, specifically in the high Andes, as a response to the growing interest in implementing strategies to conserve wetlands, and finally to present a review of the related background. This paper is divided into: Review Methodology, which presents the way in which the search was carried out, the search equations used, the inclusion and exclusion criteria. Then, the results of the background search are presented, and finally a conclusion section.

\section{METHODOLOGY}

\subsection{Review structure}

In order to define a structure for the review of the related background, some questions were posed, and allowed to address the review from a macro level (general): environmental applications of the IoT, to a micro level (more specific): environmental applications in high Andean wetlands of the IoT. The questions mentioned were:

- How has IoT's involvement in environmental solutions been?

- What have been the main contributions of the IoT to wetland monitoring?

- Has IoT been applied in the monitoring of high Andean wetlands?

The questions posed, allowed to visualize an initial structure of background search as shown in Figure 1.

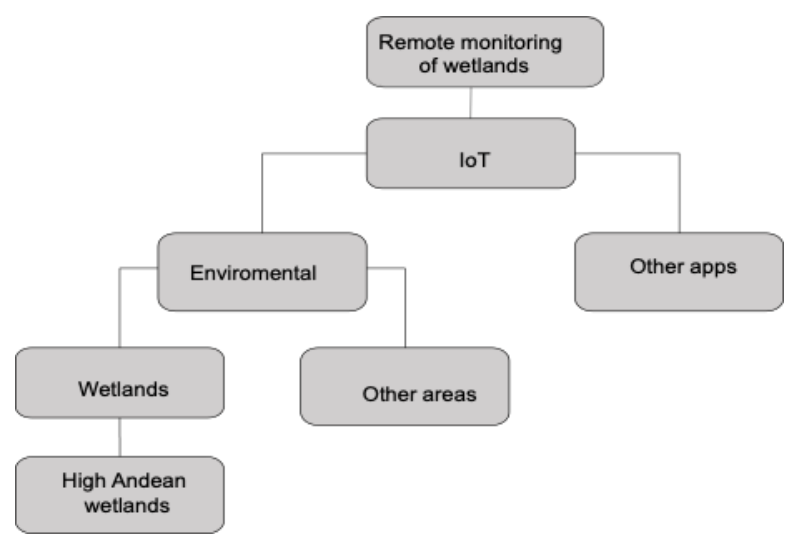

Figure 1. Initial structure for the background search 
The initial search structure in Figure 1, meets the condition of going from macro to micro in the review. Being so, initially it was started in the application area, which is the IoT. The area of the IoT, is subdivided in diverse areas where it has had application, among such areas, is the area of interest of the present paper, which is environment (macro level). Finally, at the micro level, the scheme indicates that the search should be refined, within the environment area, to the point of applications in wetlands, and specifically in high Andean wetlands.

\subsection{Data collection}

The structure shown in Figure 1, allowed the generation of an FDC type framework (fragmentingderiving-combining), which is a support for data collection. Initially, the starting point was to "facet", that is, to define facets of the background review such as: Object of Study and Theoretical Framework. Later, key words associated with the established facets are "derived". Finally, the derived key words are "combined", and the search equations are generated. The facet and derive section of this background review can be seen in Table 1. The "combine" section of the framework can be seen in Table 2. In this review, the bibliographic data used were obtained from the main WoS collection, using the search equations, given in Table 2.

Table 1. Faces of background screening

\begin{tabular}{cc}
\hline Faces & Derivade key words \\
\hline Object of study & Wetlands and their different synonyms: "wetlands", "marsh", \\
"moss", "swamp", "bog", "marshland", "moorland", "slough" \\
$\begin{array}{c}\text { Theoretical framework } \\
\text { Technology }\end{array}$ & "Internet of things", "Web of things", "WSN" \\
\hline
\end{tabular}

Table 2. Search equations

("Internet of things" OR "Web of things" OR "IoT")

( ( "Internet of things" OR "Web of things" OR "WSN" ) AND ( "wetlands" OR "marsh" OR "moss" OR "swamp" OR "bog" OR "marshland" OR "moorland" OR "slough" ) )

As inclusion criteria, for the bibliographic data, were defined: papers published in peer-reviewed journals, in English language. The exclusion criteria were the following: Informal literature, non-scientific publications, languages other than English, conference proceedings. Papers that did not meet the established criteria were eliminated as they were outside the scope of this review.

\section{RESULTS AND DISCUSSION}

The annual scientific production of the IoT began in 2002, and since then has shown a significant increase from 2012 to the present, as can be seen in Figure 2. Although, according to CISCO [9], the IoT was born somewhere between 2008 and 2009, the scientific production related to the subject, according to Figure 2 begins in 2002, with the publication: "The IoT" by Schoenberger, [22] that publication, mentions the developments of some companies, related to the optimization of the supply chain, from the use of RFID technology, which for the moment was seen as the IoT. One of the following publications, previous to the emergence of IoT according to CISCO, was made in 2004, by Gershenfeld [23], where he relates the beginnings of the IoT, and mentions how the elements that started the internet led to a new type of network of everyday devices, an "Internet-0" (I0). This I0 will allow things to exchange information between themselves and with computers, according to the needs of the systems.

What Gershenfeld described, is being lived at present, having devices "things" that are connected to each other, sharing and obtaining information, which is used to channel research in different areas of knowledge, so that the IoT has been applied, in about 79 areas. In Figure 3, it is possible to observe the 25 most relevant areas of application.

One of the 25 research areas in Figure 3 is Environmental Sciences Ecology, which is ranked 13th, with a total of 186 publications. The publications in this area, associated with IoT, began in 2013, then in 2014 there was a decrease in the annual scientific production, and since 2015 there has been a tendency to increase until 2019, see Figure 4. This made possible to define an additional inclusion criterion, which was to consider papers published from 2013 to 2019.

Once the previous criteria of additional inclusion is defined, and following the initial structure for the background search as shown in Figure 1, the background search was carried out at the third level of the scheme, relating the Internet of things with the keyword wetlands and their different synonyms, through the 
equation: (("Internet of things" OR "Web of things") AND ("wetlands" OR "marsh" OR "moss" OR "swamp" OR "bog" OR "marshland" OR "moorland" OR "slough")). The previous search equation gives 3 results in WoS, which are not related to the topic discussed in this review, therefore, are excluded leaving no background of scientific papers on this topic.

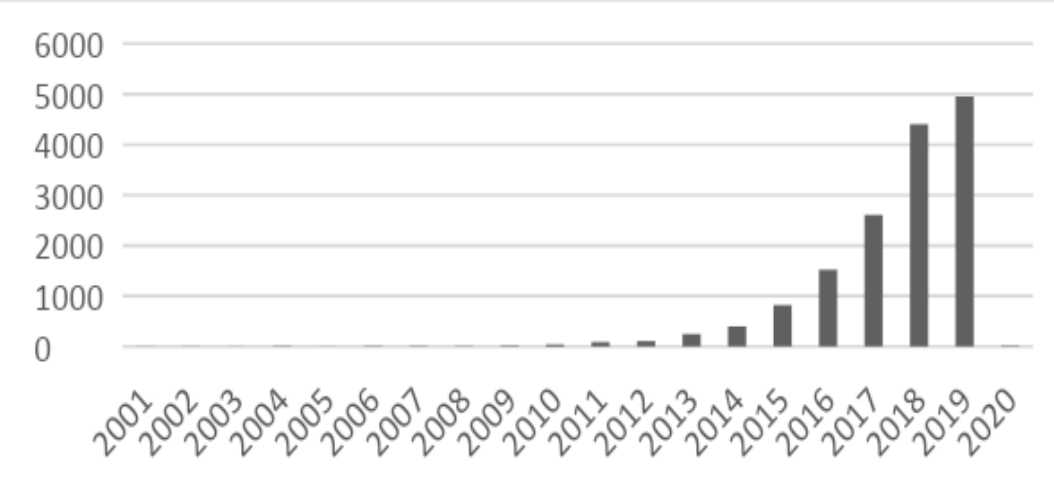

Figure 2. Annual scientific output in the IoT area, window 2002-2019 (Data source: Web of science)

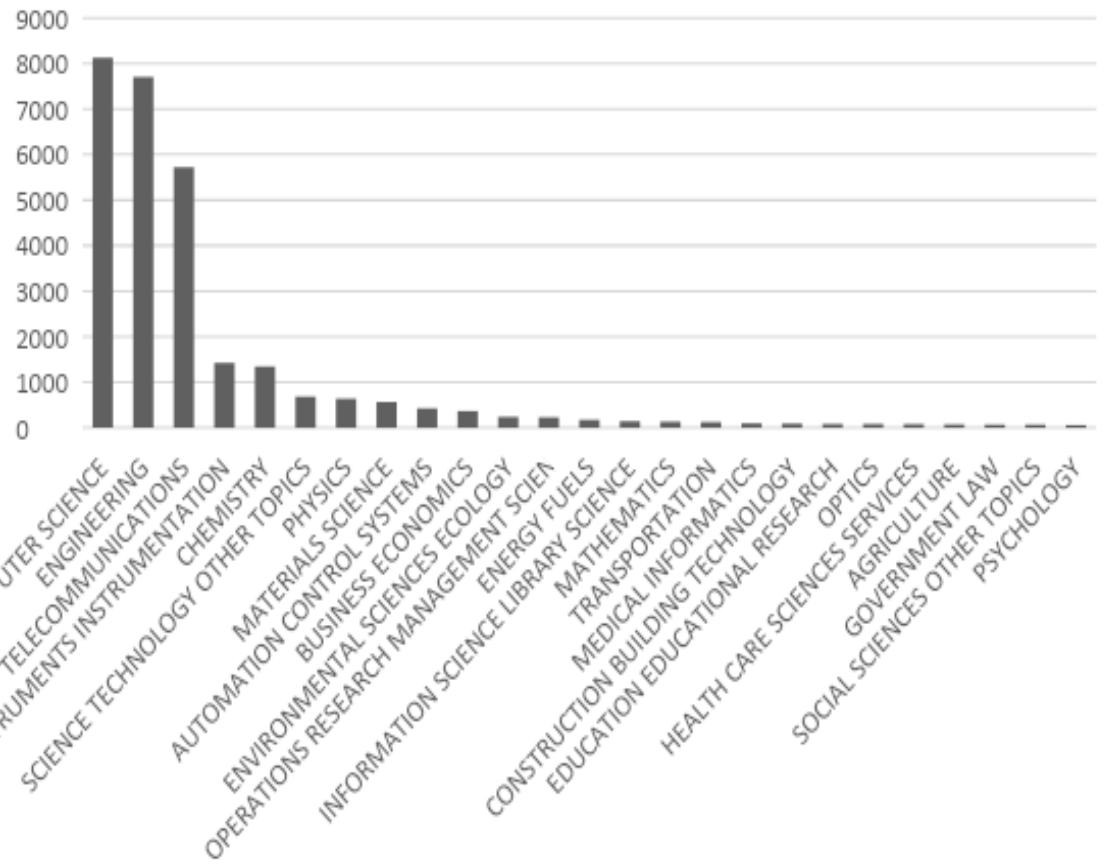

Figure 3. The 25 most important research areas in IoT (Data source: Web of science)

Given the previous result of the review, the term wireless sensor networks (WSN), was included in the search equation. Whereas the IoT is the connection of "things" to the internet, i.e., a wide area network WAN, and WSNs are networks of sensors that allow information to be obtained wirelessly, but do not necessarily connect to the internet, i.e., they connect sensors in a local area network [24]. Consequently, there may be papers, about remote wetland monitoring systems implemented in a local area (WSN solution), rather than in a wide area (IoT solution). Therefore, the scheme in Figure 1 is modified, removing the IoT applications in wetland monitoring, at the level of scientific publications, and incorporating WSN applied in wetland monitoring, see Figure 5.

The internet of things in high andean wetland monitoring, historical review... (Vladimir Henao Céspedes) 


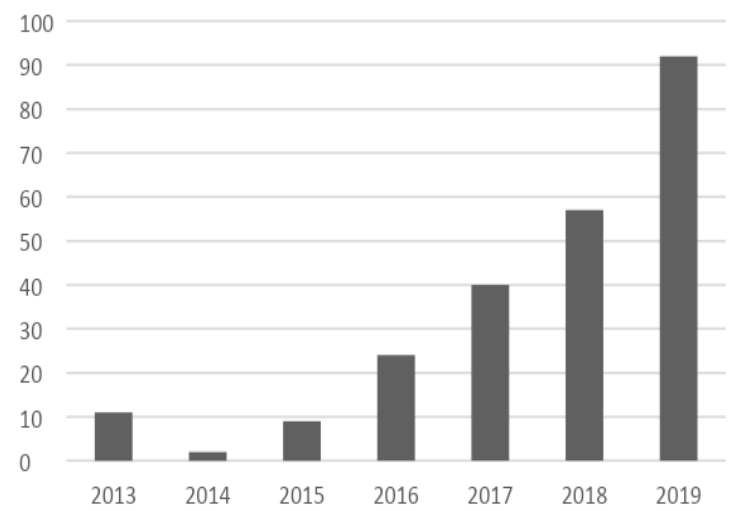

Figure 4. Temporary distribution of scientific publications on the IoT and environmental sciences ecology (Data source: Web of science)

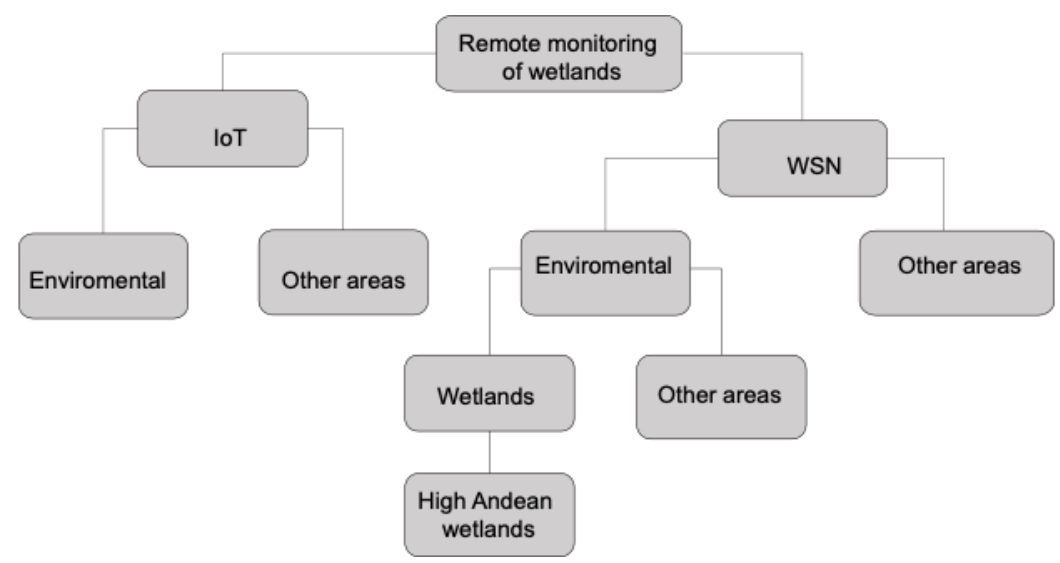

Figure 5. Modified scheme of areas of knowledge, as a consequence of results

In relation to Figure 5, the resulting search equation, including WSN, is: ("Internet of things" OR "Web of things" OR "WSN") AND ("wetlands" OR "marsh" OR "moss" OR "swamp" OR "bog" OR "marshland" OR "moorland" OR "slough")). With the present equation there are 5 results in the WOS baseline, from these results, 3 papers are filtered as not related to the present review, obtaining 2 papers that meet the criteria of the review raised, these being the ones that make up the state of the art.

The first paper, published in 2013 [25], in which the authors evaluate two WSN solutions, one commercial, and one made by students. Both solutions monitor wetland water level, precipitation, evapotranspiration, and water storage, along with mass concentration of ionic solutes (specific conductance) and chromophore dissolved organic carbon. The authors sampled at a frequency of 4-2 samples per hour. Because of the sampling frequency, the researchers observed a rapid infiltration of precipitation into the peatlands, which were surrounded by land that was used for commercial timber harvesting. They conclude that future wetland observatories would benefit from automation and standardization of data management and analysis protocols. Data management, processing and dissemination represent a major challenge because the volume of data from integrated sensor networks can grow rapidly. This is made possible by WSNs, which provide information on the hydrology, geochemistry and sensitivity to wetland disturbance.

In 2017, an paper was published [26], in which, the authors present a WSN solution implemented to monitor environmental conditions, related to temperature and light intensity variations, and how these modified the level of dissolved oxygen added by Typha latifolia and Phragmites australis in wetlands. The wetlands under analysis, in the paper described, are constructed wetlands (CW's), for the discharge of wastewater. According to the authors, WSNs are ideal in environmental detection applications because of the following conditions: small size and accuracy of data detection, high sampling frequency, ready-to-deploy nodes that operate with low power consumption. The WSN solution, designed in the paper discussed, has 
three nodes, which were equipped with sensors: Temperature, humidity and light intensity. The communication between the nodes and the receiving station was achieved with wireless transmitters and receivers at $2.4 \mathrm{GHz}$. The data are displayed on a website, at a 10-minute interval, and are stored for further analysis by the researchers. The data obtained, from the WSN, allowed them to conclude that the ideal temperature and light intensity for T. latifolia to release maximum oxygen, is in the range of $30^{\circ} \mathrm{C}$ to $35^{\circ} \mathrm{C}$ and $15000 \mathrm{~lx}$ respectively. For P. australis the optimum conditions are a temperature of $35^{\circ} \mathrm{C}$ and a light intensity between 10,000 $\mathrm{lx}$ and 15,000 lx. They also conclude, that the release of dissolved oxygen from plant roots was associated with the process of photosynthesis and the adjustment of the optimal temperature and light intensity favorable to photosynthesis helped to increase the dissolved oxygen released from plant roots, which consequently improved the efficiency of constructed wetlands.

Finally, and after analyzing the 2 papers related to the topic that concerns this work, it is possible to answer, in the following way, the questions initially raised. First, IoT has had a wide participation in environmental solutions, which is reflected by the 186 publications that relate IoT and environmental sciences ecology. Second, according to the review carried out, IoT has not been involved in wetland monitoring, at least this is how it appears from the scientific production published in journals. Given the above and accepting that a solution from the IoT can be confused with a solution from the WSNs and considering that their difference lies in the coverage areas (wide and local respectively), the literature on WSNs and their application in wetland monitoring was analyzed. Finally, as reflected in the review, neither the IOT nor the WSNs have been applied in the monitoring of high Andean wetlands.

\section{CONCLUSION}

The main objective of this paper was to provide a review of the background of the environmental applications of the IoT, by proposing a search methodology in an international reference base. Therefore, some conclusions were obtained based on the results obtained from the search and the problems presented during the search.

In the first place, the term IoT arises since 2002, at least at the level of publications and future visualizations on the behavior of technology, but it is only, until a moment between 2008 and 2009, according to CISCO [9], where one could think that it arises at a technological level, that is, it is at that point in history where the IoT materializes, and different applications begin to thrive.

Secondly, it is possible to visualize that the IoT has been present in environmental applications since 2013, but these have not been related to wetlands. Given the above, the first and only problem of the proposed revision is presented, which makes it take a direction towards the environmental applications of WSNs, which is not far from the IoT, considering that the difference between both technologies is the space of coverage of their applications and the transport of the data to the internet network.

Thirdly, in modifying the search structure to include WSNs, there are publications focused on wetland applications, which agree on the importance of WSNs for their low cost, high sampling frequency, low power consumption, and ease of deployment of nodes. It should be noted that at the level of high Andean wetlands, the application of WSNs is still non-existent, which leaves an area of research completely open.

Finally, the IoT could be a technological tool that would help enormously in the research and understanding of the dynamics of wetlands, and especially high Andean wetlands, and their relationship with climate change, and which, at least from the literature, has not been sufficiently explored.

\section{ACKNOWLEDGEMENTS}

The author thanks Universidad Católica de Manizales with the Research Group on Technological and Environmental Development GIDTA and Education and Educators Traning EFE.

\section{REFERENCES}

[1] Secretaría de la Convención de Ramsar, "Uso racional de los humedales: Conceptos y enfoques para el uso racional de los humedales," Manuales Ramsar para el uso racional de los humedales, vol. 1, no. 4, p. 64, 2010.

[2] A. J. Benfield, Z. Yu, and J. C. Benavides, "Environmental controls over Holocene carbon accumulation in Distichia muscoides-dominated peatlands in the eastern Andes of Colombia," Quaternary Science Reviews, vol. 251, 2021, doi: 10.1016/j.quascirev.2020.106687.

[3] Fundación Pangea and Corpocaldas, "Informe de la Caracterización de Humedales en el proyecto Conservación de Humedales Altoandinos en cinco municipios del Departamento de Caldas: Neira, Salamina, Villamaría, Manizales y Marulanda," Manizales, Colombia: Fundación Pangea y Corpocaldas, 2007.

[4] G. Y. Florez-Yepes, J. F. Betancur-Pérez, F. Monterroso-Tobar, and J. Londoño-Bonilla, "Temporary wetland evolution in the upper Chinchiná river basin and its relationship with ecosystem dynamics," DYNA, vol. 85, pp. 351-359, 2018, doi: 10.15446/dyna.v85n207.69963.

The internet of things in high andean wetland monitoring, historical review... (Vladimir Henao Céspedes) 
[5] M. Guo, J. Li, C. Sheng, J. Xu, and L. Wu, "A review of wetland remote sensing," Sensors (Switzerland), vol. 17, no. 4, pp. 1-36, 2017, doi: 10.3390/s17040777.

[6] J. Chin, V. Callaghan, and S. Ben Allouch, "The Internet-of-Things: Reflections on the past, present and future from a user-centered and smart environment perspective," Journal of Ambient Intelligence and Smart Environments, vol. 11, no. 1, pp. 45-69, 2019, doi: 10.3233/AIS-180506.

[7] A. A. Abbood, Q. M. Shallal, and M. A. Fadhel, "Internet of things (IoT): A technology review, security issues, threats, and open challenges," Indonesian Journal of Electrical Engineering and Computer Science, vol. 20, no. 3, pp. 1685-1692, 2020, doi: 10.11591/ijeecs.v20.i3.pp1685-1692.

[8] A. Rghioui and A. Oumnad, "Internet of things: Surveys for measuring human activities from everywhere," Int. J. Electr. Comput. Eng International Journal of Electrical and Computer Engineering, vol. 7, no. 5, pp. 2474-2482, 2017, doi: 10.11591/ijece.v7i5.pp2474-2482.

[9] D. Evans and Cisco Internet Business Solution Group (IBSG), "Internet de las cosas Internet de las cosas. Cómo la próxima evolución de Internet lo cambia todo," 2011.

[10] V. Reddy and G. P, "Integration of internet of things with wireless sensor network," International Journal of Electrical \& Computer Engineering, vol. 9, no. 1, p. 439, 2019, doi: 10.11591/ijece.v9i1.pp439-444.

[11] J. Kaur and K. Kaur, "Internet of Things: A Review on Technologies, Architecture, Challenges, Applications, Future Trends," International Journal of Computer Network \& Information Security, vol. 9, no. 4, pp. 57-70, 2017, doi: 10.5815/ijcnis.2017.04.07.

[12] A. A. Jaber, F. K. I. Al-Mousawi, and H. S. Jasem, "Internet of things based industrial environment monitoring and control: A design approach," International Journal of Electrical \& Computer Engineering, vol. 9, no. 6, pp. 4657 4667, 2019, doi: 10.11591/ijece.v9i6.pp4657-4667.

[13] R. A. Rahman, U. R. Hashim, and S. Ahmad, "IoT based temperature and humidity monitoring framework," Bulletin of Electrical Engineering and Informatics, vol. 9, no. 1, pp. 229-237, 2020, doi: 10.11591/eei.v9i1.1557.

[14] M. U. H. Al Rasyid, M. H. Mubarrok, and J. A. N. Hasim, "Implementation of environmental monitoring based on kaa iot platform," Bulletin of Electrical Engineering and Informatics, vol. 9, no. 6, pp. 2578-2587, 2020, doi: 10.11591/eei.v9i6.2578.

[15] S. Noorjannah Ibrahim, A. L. Asnawi, N. Abdul Malik, N. F. Mohd Azmin, A. Z. Jusoh, and F. N. Mohd Isa, "Web based water turbidity monitoring and automated filtration system: IoT application in water management," International Journal of Electrical \& Computer Engineering, vol. 8, no. 4, pp. 2503-2511, 2018, doi: 10.11591/ijece.v8i4.pp2503-2511.

[16] Z. M. Yusof, M. M. Billah, and K. Kadir, "Real-time water quality monitoring system: An IoT application," Indonesian Journal of Electrical Engineering and Computer Science, vol. 15, no. 1, pp. 178-182, 2019, doi: 10.11591/ijeecs.v15.i1.pp178-182.

[17] V. Cooray, "Mechanism of the lightning flash," in The Lightning Flash, Second., V. Cooray, Ed. London, United Kingdom: The Institution of Engineering and Technology, 2014.

[18] M. A. A. Aziz, M. F. Abas, M. K. A. Abu Bashri, N. M. Saad, and M. H. Ariff, "Evaluating IoT based passive water catchment monitoring system data acquisition and analysis," Bulletin of Electrical Engineering and Informatics, vol. 8, no. 4, pp. 1373-1382, 2019, doi: 10.11591/eei.v8i4.1583.

[19] A. H. Miry and G. A. Aramice, "Water monitoring and analytic based ThingSpeak," International Journal of Electrical \& Computer Engineering, vol. 10, no. 4, pp. 3588-3595, 2020, doi: 10.11591/ijece.v10i4.pp3588-3595.

[20] D. Gupta, A. Parikh, and R. Swarnalatha, "Integrated healthcare monitoring device for obese adults using internet of things (IoT)," International Journal of Electrical \& Computer Engineering, vol. 10, no. 2, pp. 1239-1247, 2020, doi: 10.11591/ijece.v10i1.pp1239-1247.

[21] M. M. M. Al-Omri, N. A. M. Alduais, M. N. Adon, A. M. H. Y. Saad, A. S. H. Abdul-Qawy, and T. Sutikno, "Internet of things-based telemonitoring rehabilitation system for knee injuries," Bulletin of Electrical Engineering and Informatics, vol. 9, no. 6, pp. 2658-2666, 2020, doi: 10.11591/eei.v9i6.2428.

[22] C. R. Schoenberger and B. Upbin, "The internet of things," Forbes Magazine, vol. 169, no. 6, pp. 155-160, 2002.

[23] N. Gershenfeld, R. Krikorian, and D. Cohen, "The internet of Things," Scientific American, vol. 291, no. 4, pp. 7681,2004

[24] J. Ruiz-Rosero, G. Ramirez-Gonzalez, J. M. Williams, H. Liu, R. Khanna, and G. Pisharody, "Internet of things: A scientometric review," Symmetry, vol. 9, no. 12, 2017, doi: 10.3390/sym9120301.

[25] C. J. Watras, M. Morrow, K. Morrison, and S. Scannell, "Evaluation of wireless sensor networks (WSNs) for remote wetland monitoring: Design and initial results," Environmental Monitoring and Assessment, vol. 186, no. 2, pp. 919-934, 2014, doi: 10.1007/s10661-013-3424-8.

[26] F. Rehman, A. Pervez, Q. Mahmood, and B. Nawab, "Wastewater remediation by optimum dissolve oxygen enhanced by macrophytes in constructed wetlands," Ecological Engineering, vol. 102, pp. 112-126, 2017, doi: 10.1016/j.ecoleng.2017.01.030. 


\section{BIOGRAPHIES OF AUTHORS}

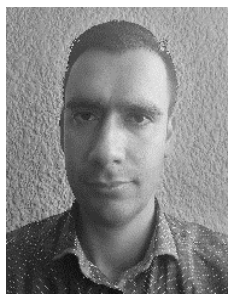

Vladimir Henao Céspedes: received the B.S degree in electronic engineering, the M.Sc. degree and the $\mathrm{PhD}$. on engineering from Universidad Nacional de Colombia, Manizales. He currently an Associated Professor, UAFCNM at Universidad Católica de Manizales, Manizales, Colombia. E-mail:vhenao@ucm.edu.co. His research interests include electromagnetic compatibility, electromagnetic pollution, lightning discharges, and Internet of Things. He is member of the research group in tecnhonological and environmental development GIDTA. http://orcid.org/0000-0002-1938-3203

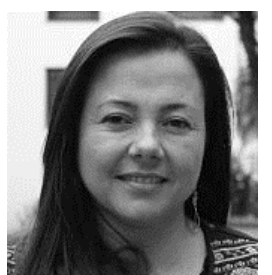

Gloria Yaneth Florez: is BSc. in Environmental Administrator, MSc. Sustainable Development and the Environment, PhD. Sustainable Development. Professor at the Universidad Católica de Manizales Colombia, coordinator in the research group on Technological and Environmental Development. http://orcid.org/0000-0003-4185-017

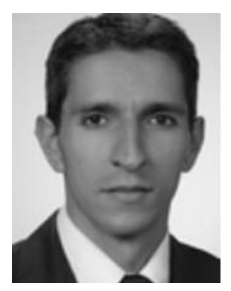

Yeison Alberto Garcés-Gómez: Electronic Engineer, M.Sc (Eng) Industrial Automation, Ph.D. on Engineering. Associated Professor, UAFCNM, Universidad Católica de Manizales, Manizales, Colombia. E-mail: ygarces@ucm.edu.co. His research interests include applied technologies to healthcare and education, power definitions under no sinusoidal conditions, power quality analysis, and power electronic applications. He is member of the Research Group on Tecnhonological and Environmental Development GIDTA and Education and Educators Traning EFE. http://orcid.org/0000-0002-9409-3652 